\title{
ВЛИЯНИЕ РЕМИТТАНСОВ НА СОЦИАЛЬНО-ЭКОНОМИЧЕСКОЕ РАЗВИТИЕ КЫРГЫЗСКОЙ РЕСПУБЛИКИ В УСЛОВИЯХ ПАНДЕМИИ
}

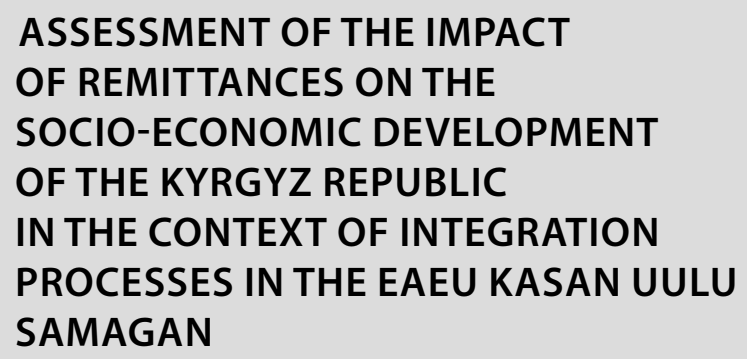

ASSESSMENT OF THE IMPACT

OF REMITTANCES ON THE

SOCIO-ECONOMIC DEVELOPMENT

OF THE KYRGYZ REPUBLIC

IN THE CONTEXT OF INTEGRATION PROCESSES IN THE EAEU KASAN UULU SAMAGAN

\section{Kasan uulu Samagan} V. Abramov

Summary. The article analyzes the impact of remittances (remittances) of labor migrants on the socio-economic development of Kyrgyzstan. The positive and negative factors of the impact of remittances, the consequences of the COVIND-19 pandemic and the political situation in the country are revealed. Measures to replace labor migration to strengthen the positive effects on the country's economy in the conditions of the EAEU are proposed.

Keywords: labor migration, money transfers, remittances, integration processes of the EAEU, replacement of labor migration, direct investment in Kyrgyzstan.

\author{
Касан уулу Самаган \\ Аспирант, Финансовый университет при \\ Правительстве РФ, Москва \\ samagan94@gmail.com \\ Абрамов Валерий Леонидович \\ Д.э.н., г.н.С., Институт исследований
}

международных экономических отношений; профессор, Финансовый университет при Правительстве РФ,

Москва

vlabramov@fa.ru

Аннотация. В статье проанализировано влияние денежных переводов (ремиттансов) трудовых мигрантов на социально-экономическое развитие Кыргызстана. Раскрыты позитивные и негативные факторы в0здействия ремиттансов, последствия пандемии COVID-19 и политической ситуации в стране. Предложены меры замещения трудовой миграции для усиления положительных эффектов на экономику страны в условиях ЕАЭС.

Ключевые слова: трудовая миграция, денежные переводы, ремиттансы, интеграционные процессы, ЕАЭС, замещение трудовой миграции, прямые инвестиции в Кыргызстан. огласно данным Всемирного банка Кыргызстан, устойчиво находится в группе 7 стран с самой высоким соотношением денежных переводов к ВВП, наряду с такими странами как Ливан, Судан, Непал, Таджикистан. Такая особенность характерна для государств с низким уровнем экономического развития.

Миграция в Кыргызской Республике, как и в прошлые периоды, характеризуется высоким уровнем оттока трудоспособного населения. В 2018 году более 700 тыс. граждан были поставлены на миграционной учет в странах пребывания, что составляет более $10 \%$ всего населения республики. Основной поток граждан, выезжающих на заработки, направлен на Российскую Федерацию, на долю которой приходится более $86 \%$ трудовых мигрантов. [1]

При этом в 2019 году число граждан, выехавших за рубеж для постоянного места жительства увеличилось на 14,3\% по сравнению с 2018 годом. За период с 2011-2020 года чистый миграционный отток граждан Кыргызстана составлял ежегодно 85 тыс. человек. [2]
Такие значительные миграционные процессы оказывают существенное воздействие на экономику, прежде всего путем отправления ремиттансов на родину. Средняя сумма ежемесячных денежных переводов одного трудового мигранта составляет 536 долл. США, что является для многих домохозяйств ощутимым источником дохода.[3] Отметим, что сумма ежемесячного прожиточного минимума в Кыргызстане не превышает 100 долл. США за 2020 год, поэтому благодаря значительным ремиттансам трудовых мигрантов, многие домохозяйства способны поддерживать достойный уровень жизни в краткосрочной перспективе.

Из данных Таблицы 1. видно, что суммы денежных переводов трудовых мигрантов являются стабильно значительными и составляют в медианном значении ежегодный объем в интервале от 2 до 2.5 млрд. долл. США. Существенное отклонение отмечается лишь в 2015 году, что обусловленных в основном воздействием внешних факторов на российскую экономику (экономические санкции, падение цен на продукты экспорта). Ее состояние играет ключевую роль для объ- 
Таблица 1. Динамика объемов денежных переводов трудовых мигрантов в Кыргызстан в 2012-2020 гг.[4]

\begin{tabular}{|l|l|l|l|l|l|l|}
\hline Период (года) & 2014 & 2015 & 2016 & 2017 & 2018 & 2019 \\
\hline ВВП (млн. долл. США) & 7468 & 6633 & 6864 & 7701 & 8276 & 8870 \\
\hline Суммы ремиттансов (млн. долл. США) & 2236 & 1684 & 1991 & 2482 & 2685 & 2407 \\
\hline Соотношение ремиттансов к ВВП (\%) & $29,9 \%$ & $25,4 \%$ & $29,0 \%$ & $32,2 \%$ & $32,4 \%$ & $27,1 \%$ \\
\hline
\end{tabular}

емов ремиттансов, так как основные потоки денежных переводов исходят из России, составляя около 98\% всего объема денежных переводов.[4] Наблюдается их поступательный рост на протяжении 2016-2018 гг. Пик приходится на 2018 год, когда - размер денежных переводов трудовых мигрантов составил 2,6 млрд. долл. США. После вступления Кыргызстана в Евразийский экономический союз его граждане получили определенные облегчения в условиях пребывания в РФ (отпала необходимость получения разрешения на работу и уплаты обязательного патента). В 2019-2020 году, несмотря на влияние COVID-19, сумма переводов оставалась не ниже 2,3 млрд. долл. США.

В 2019 году сумма переводов физических лиц составила более 2,4 млрд. долларов США, что составляет более $28 \%$ ВВП. Данное обстоятельство представляется весьма значимым, учитывая что за 2019 г. чистой приток иностранных инвестиций, включая получение иностранных кредитов составил лишь 406 млн. долларов США.[5]

Из данных таблицы 1. видно, что рост объемов денежных переводов коррелируется с ростом странового ВВП. Так, в 2017 году сумма денежных переводов увеличилась на 24\%, при этом ВВП вырос на 12\%,

В 2020 году на объемы ремиттансов трудовых мигрантов сказалось влияние пандемии.

Локдаун, вызванный пандемией COVID-19, существенно сократил возможности миграции в Россию и Казахстан. Если смотреть на экономическое положение Кыргызстана в 2020 году через призму миграции, то первая половина года характеризуется стремлением граждан вернуться на родину в связи с экономическими последствиями локдауна: закрытие предприятий и потеря работы, несвоевременные или неполные выплаты заработной платы, невозможность получения медицинской помощи. Вследствие чего за указанный период сумма денежных переводов снизилась на 13\% по сравнению с аналогичным периодом прошлого года, отмечается и падение ВВП страны на 9,49\% Вторая половина 2020 года характеризуется увеличением трудовой активности мигрантов в связи с поэтапным снятием ограничительных мер. Объемы ремиттансов, соответ- ственно, увеличилась на 9,33\% по сравнению с аналогичным периодом прошлого периода.

Многие киргизские предприниматели вынуждены были приостановить свою деятельность в период локдауна, что сказалось на снижении показателей внешней торговли на 18\%, снижении объемов ВВП на 8,1\% по сравнению предыдущим периодом. Оценивая перспективы роста ремиттансов киргизских трудовых мигрантов, следует иметь в виду экономический кризис, вызванный COVID-19, который по оценкам будет носить долгосрочный и всеобъемлющий характер.[6] Согласно прогнозам Всемирного Банка, новые вспышки коронавируса в мире возможно будут сопровождаться новыми локдаунами, запретами на перелеты и социальным дистанцированием.[7] Экономическая активность, уровень занятости во всем мире постепенно будут восстанавливаются, но по прогнозам уровень международной миграции в текущем году существенно сократиться и скорее будет носить возвратный характер. Неблагоприятные последствия кризиса с точки зрения потери рабочих мест и заработков, а также подверженности воздействию COVID-19 и заражения им были непропорционально высоки для мигрантов, особенно для тех, кто работает в неформальном секторе и на низкоквалифицированных рабочих местах. Многочисленные сообщения свидетельствуют о том, что мигранты, особенно те, кто живет в общежитиях или лагерях, в большей мере уязвимы к риску заражения вирусом COVID-19.

Исходя из прогнозных сценариев экономической деятельности в в Соединенных Штатах, европейских странах и странах Совета сотрудничества стран Персидского залива, потоки денежных переводов в страны с низким и средним уровнем дохода по прогнозам сократятся до 470 миллиардов долларов в 2021 году. [8] Прогнозируемое сокращение денежных переводов стало самым значительным в новейшей истории и превысило 5\%. Аналогичный спад был зафиксирован только во время глобальной рецессии 2009 года.

Перспективы денежных переводов остаются неопределенными и будут зависеть от влияния COVID-19 на глобальный рост. Это, в свою очередь, связано с неопределенностью в отношении эффективности усилий по сдерживанию распространения болезни. 
Перейдем к анализу экономических последствий для трудовой миграции в Кыргызстане в долгосрочной перспективе. Отметим, что она

для большинства граждан является вынужденной мерой решения своих экономических проблем.

В качестве положительных эффектов стоит отметить, что значительный приток ремиттансов стабилизирует национальную экономику и бесспорно поддерживает уровень жизни домохозяйств. Ремиттансы, как правило, расходуются семьями трудовых мигрантов на покрытие своих текущих расходов, что способствует развитию соответствующих отраслей: сфера оптово-розничной торговли, сфера услуг, строительство, некоторые сферы легкой промышленности. Однако при этом денежные средства достаточно редко направляются на создание новых производственных мощностей в самой стране, а расходуются на приобретение потребительских товаров.

В качестве негативного влияния на социально-экономическое развитие страны чистый приток денежных переводов трудовых мигрантов имеет эффект, сопоставимый с голландской болезнью: наблюдается значительный рост расходов по отношению к ВВП, увеличение доли сферы услуг, слабая динамика экспорта и относительно высокие показатели импорта. Исследователи обращают внимание на то, что существуют пороговые значения отношения суммы денежных переводов к ВВП, превышение которых возможно усиливают негативные последствия для экономики.[9]

В рамках интеграционного взаимодействия между странами в ЕАЭС отсутствуют законодательные барьеры, а уровень издержек для трудоустройства остается низким, поэтому можно прогнозировать в рост перетока национальных кадров высокой квалификации в более благополучные страны интеграционного объединения. При этом в долгосрочной перспективе принимающая страна выигрывает от трудовой миграции квалифицированных сотрудников, так как расходы предпринимателей на оплату труда снижаются, в тоже время расходы предпринимателей по оплате труда в Кыргызстане будут склонны к увеличению. Данный тезис подтверждается опытом западных принимающих стран, где наблюдался высокий уровень трудовой миграции квалифицированных кадров.[10]

Не стоит забывать о социальных последствиях трудовой миграции. В ее составе большинство составляют молодые граждане от 20-29 лет. Они, учитывая культурные и этические нормы региона, чаще всего уже связаны узами брака и имеют детей, которых оставляют на попечение близких родственников. Зачастую мигранты, получив среднее школьное образование, отправляются на заработки за рубеж, не получив определенную специализацию или высшее образование. По статистическим данным, 56\% занятых в национальной экономике составляет молодежь в возрасте от 20 до 29 лет, из них только 13,8\% -имеют высшее образование, более 70\% имеют лишь школьное образование.

В связи с отсутствием соответствующих навыков и опыта, большинство трудовых мигрантов из Кыргызстана вынуждены заниматься низкоквалифицированным трудом, с невысокой оплатой и ухудшенными условиями труда. При этом исследователями отмечается, что данное обстоятельство не является барьером для трудоустройства в принимающей стране. Большинство киргизских трудовых мигрантов задействованы в сферах строительства и услуг, где они ощущают определенный уровень дискриминации по заработной плате. Отчасти оно обусловлено низким уровнем квалификации, недостаточным уровнем осведомленности об уровне заработной платы, незнанием трудового законодательства. Указанные проблемы мене менее актуальны для высококвалифицированных мигрантов, они чаще всего проходят отбор на равных условиях с другими специалистами и более востребованы благодаря своим компетенциям и опыту. Часть из них, получив желаемую должность в принимающей стране и более высокую оплату труда, остается в принимающей стране на постоянное проживание. Основной мотив - это то, что среднемесячная заработная плата в Кыргызстане не может удовлетворить их потребности.

Для нейтрализации негативных последствий трудовой миграции, а в целях получения положительного эффекта на социально-экономическое развитие Кыргызстана в рамках ЕАЭС обосновываются следующие предложения.

Во-первых, одним из способов замещения трудовой миграции могут стать прямые иностранные инвестиции (ПИИ) и открытие дочерних предприятий транснациональных компаний на территории Кыргызской Республики. По оценкам Бостонской консалтинговой группы сумма ПИИ в несырьевые отрасли Кыргызстана могут достичь 2 млрд. долл. США до 2027 г.[11] Инвестиции помогут создать значительные инфраструктурные преобразования, снизить поток низкоквалифицированной рабочей силы и создать новые рабочие места в самой республике. Условием для этого может стать создание реальных гарантий по защите иностранного бизнеса от национализации и иных рисков, связанных с защитой их интересов.

Во-вторых, другой современной формой замещения миграции является оказание услуг путем аутсорсинга, актуальность которого усилилась под воздействием панде- 
мии COVID-19. Дистанционное оказание услуг может стать подспорьем в замещении миграции. Аргументом может служить, что в более развитых странах предприниматели находятся в поисках более дешевой рабочей силы.

В-третьих, Кыргызстан нуждается в качественном улучшении образовательных процессов. На данный момент получение высшего образования является формальным процессом, не связанным с будущим трудоустройством. В стране ежегодно выпускается более 33000 специалистов, но 70\% выпускников вузов составляют гуманитарные направления (экономика, юриспруденция, менеджмент, образование).[12] При этом Кыргызстан нуждается в специалистах технической направленности для развития приоритетных отраслей, определенных в Национальной стратегии развития: энергетического, горнодобывающих отраслей, а также в специалистах по сельскому хозяйству.[13] Зачастую выпускники в основном не могут трудоустроиться по специальности и вынуждены искать вакансии в соседних странах.

\section{Выво $\triangle \mathrm{b}$}

Кыргызская Республика относится к числу стран Центральной Азии с существенным числом трудовых мигрантов в ЕАЭС, которые составляют весомую долю всего экономически активного населения страны. Кыргызстан является одной из самых зависимых стран в мире от уровня ремиттансов.

Основной причиной миграции является: невозможность трудоустройства в Кыргызстане, низкий уровень заработной платы, туманные перспективы экономического роста.
На основе анализа динамика ремиттансов в условиях интеграционных процессов ЕАЭС за период с 2015-2020 гг. раскрыто влияние переводов на социально-экономическое развитие Кыргызской Республики. Объемы ремиттансов составляют порядка 30\% ВВП Кыргызстана, оказывают существенное влияние на развитие домашних хозяйств, повышение благосостояния населения.

Показано, что в 2020 году экономика Кыргызской Республики столкнулась с беспрецедентными падением ВВП на 8,1\%, вызванным прежде всего последствиями пандемии COVID-19 и внутренними политическими потрясениями в октябре 2020 г. Несмотря на значительные экономические трудности, объемы ремиттансов трудовых мигрантов во второй половине 2020 года вернулись к прошлогоднему уровню.

Рассмотрены возможные меры замещения трудовой миграции для увеличения положительного эффекта на экономику страны. Обоснованы предложения и рекомендации о необходимости качественного преобразования образовательных процессов в республике, увеличения числа высококвалифицированных и востребованных рынком труда кадров.

Следует также осуществить меры по улучшению инвестиционного климата путем законодательных закрепленных мер по защите интересов инвесторов, усилить возможности привлечения инвестиций из стран ЕАЭС, что позволит создать дополнительные рабочие места, снизив неблагоприятные последствия высокого уровня оттока трудовых ресурсов.

\section{ЛИТЕРАТУРА}

1. Миграционная статистика 2018. Миграционная служба при Правительстве Кыргызской Республики. URL: http://ssm.gov.kg/полезная-информация/ статистика (дата обращения 15.02.2020)

2. Статистика по миграционному приросту, оттокпо внешней миграции. Национальный статистический комитет KP. URL: http://www.stat.kg/ru/opendata/ category/41/ (дата обращения 15.02.2020)

3. Статистика по средней сумме денежных переводов мигранта. Финэкспертиза. URL: https://finexpertiza.ru/press-service/researches/2019/summa-denperevoda-migranta/ (дата обращения 15.02.2020)

4. Денежные переводы физических лиц, осуществленных через системы денежных переводов. Национальный Банк Кыргызской Республики. URL: https://www.nbkr.kg/index1.jsp?item=1785\&lang=RUS (дата обращения 17.02.2020)

5. Приток прямых иностранных инвестиций. Национальный статистических комитет. URL: http://www.stat.kg/ru/news/postuplenie-pryamyh-inostrannyhinvesticij-v-yanvare-iyune-2020-goda/

6. Прогноз ЕАБР. Замедление роста Кыргызстана ВВП 2020 г. URL: https://eabr.org/press/releases/rost-vvp-kyrgyzstana-v-2020-godu-zamedlitsya/ (дата обращенния: 15.02 .2020$)$

7. Доклад об экономике региона Европы и Центральной Азии, весна 2020 года. Всемирный банк, Вашингтон, округ Колумбия. Dоі: 10.1596/978-14648-1564-5

8. Dilip Ratha, Supriyo De, Eung Ju Kim, Sonia Plaza. Phase II: COVID-19 Crisis through a Migration Lens Migration and Development. World Bank Group. Brief review № 33. Washington, DC. October 2020, 8-20 c

9. Гиноян А.Б. Диссертация на соискание ученой степени кандидата экономических наук на тему «Миграционные процессы н макроэкономические последствия ремиттансов в странах СНГ», РАНХиГС, Москва .2017, 25 с. 
10. Рассмотрение проблем организации управления в контексте изменяющегося характера трудовой миграции, Доклад IV. Международная организация конференция труда, 2017 г. URL: https://www.ilo.org/wcmsp5/groups/public/_-ed_norm/-relconf/documents/meetingdocument/wcms_550536.pdf (Дата обращения 14.03.2020)

11. Инвестиции в Центральную Азию: один регион - множество возможностей. BCG, 2017 г. URL: https://web-assets.bcg.com/3e/30/ a2fb20c140ae8a7d8f31c2d86eed/bcg-investing-in-central-asia-report-rus-tcm27-212858.pdf (дата обращения: 14.03.2020)

12. Ежегодный статистический сборник «Кыргызстан в Цифрах». Нацстатком Кыргызской Республики. Бишкек, 2020 г. URL: http://stat.kg/ru/publications/ sbornik-kyrgyzstan-v-cifrah/ (дата обращения: 16.02.2020)

13. Национальная стратегия развития Кыргызской Республики на 2018-2040 годы. Указ президента Кыргызской Республики № 221 от 31.10 .2018 URL: https://mfa.gov.kg/uploads/content/1036/3ccf962c-a0fc-3e32-b2f0-5580bfc79401.pdf (дата обращения 13.03.2020)

( Касан уулу Самаган ( samagan94@gmail.com ), Абрамов Валерий Леонидович ( vlabramov@fa.ru ).

Журнал «Современная наука: актуальные проблемы теории и практики»

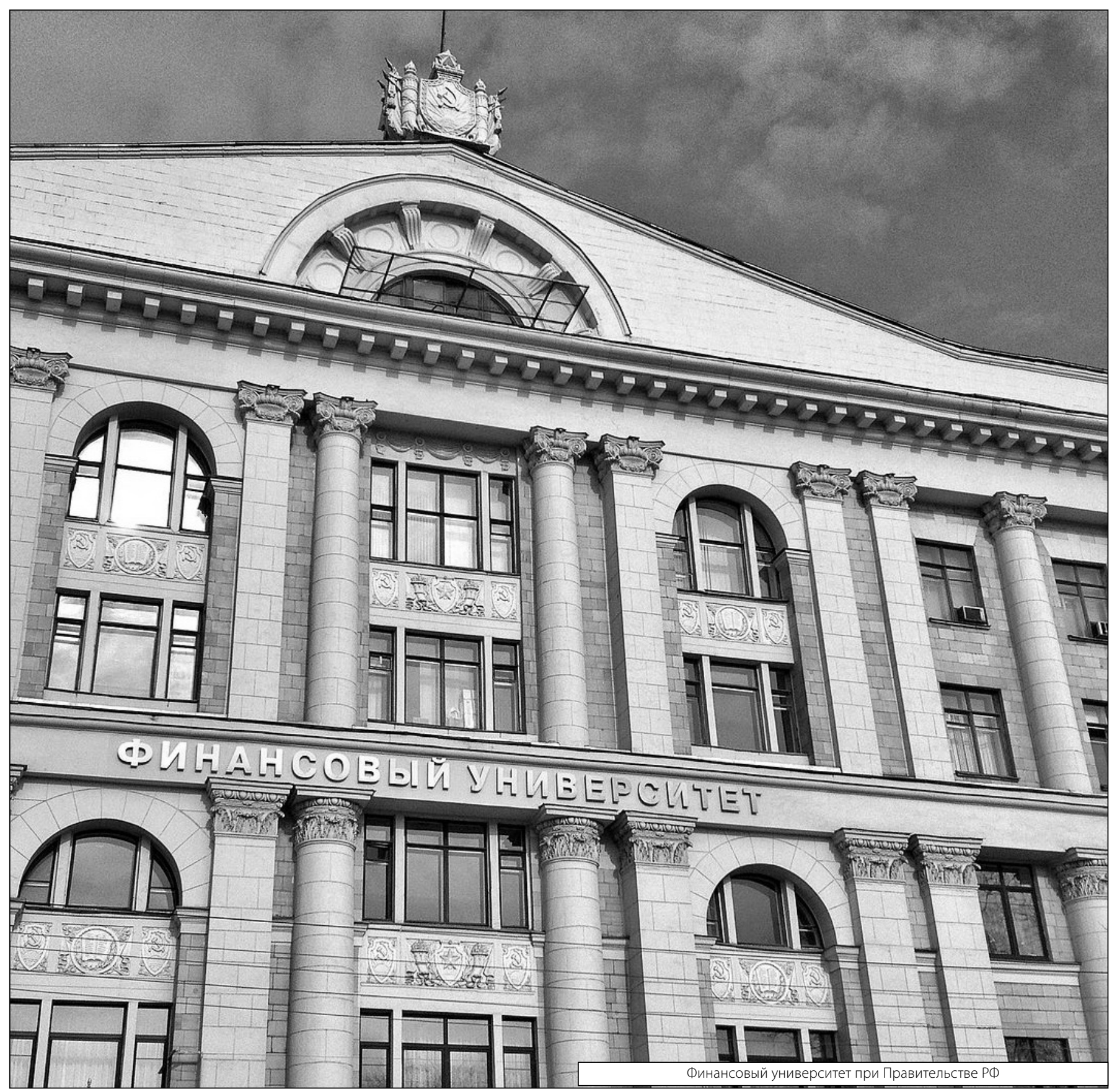

